\title{
Young people's beliefs about psychological therapy for psychosis: a Q-methodological study
}

DOI:

10.1080/09638237.2019.1677869

\section{Document Version}

Accepted author manuscript

Link to publication record in Manchester Research Explorer

\section{Citation for published version (APA):}

Holding, J. C., Haddock, G., \& Gregg, L. (2019). Young people's beliefs about psychological therapy for psychosis: a Q-methodological study. Journal of Mental Health, 29(4), 446-454.

https://doi.org/10.1080/09638237.2019.1677869

\section{Published in:}

Journal of Mental Health

\section{Citing this paper}

Please note that where the full-text provided on Manchester Research Explorer is the Author Accepted Manuscript or Proof version this may differ from the final Published version. If citing, it is advised that you check and use the publisher's definitive version.

\section{General rights}

Copyright and moral rights for the publications made accessible in the Research Explorer are retained by the authors and/or other copyright owners and it is a condition of accessing publications that users recognise and abide by the legal requirements associated with these rights.

\section{Takedown policy}

If you believe that this document breaches copyright please refer to the University of Manchester's Takedown Procedures [http://man.ac.uk/04Y6Bo] or contact uml.scholarlycommunications@manchester.ac.uk providing relevant details, so we can investigate your claim.

\section{OPEN ACCESS}




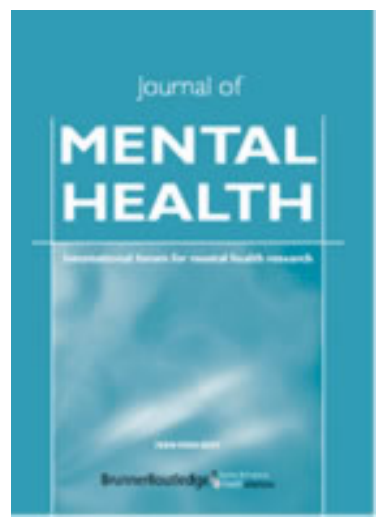

\section{Young people's beliefs about psychological therapy for psychosis: a Q-methodological study}

\begin{tabular}{|r|l|}
\hline Journal: & Journal of Mental Health \\
\hline Manuscript ID & CJMH-2018-0457.R2 \\
\hline Manuscript Type: & Original Article \\
\hline Subject Area: & Psychosis \\
\hline Further Detail: & Individual therapy \\
\hline \multicolumn{2}{l}{} \\
\end{tabular}

\section{SCHOLARONE Manuscripts}


Abstract

Background: The evidence base for the use of psychological therapies in the treatment of psychosis is growing, however engagement can be difficult and outcomes are variable. Beliefs, attitudes and expectations may have an important influence on whether individuals engage with therapy and on clinical outcomes, however, these beliefs have not been adequately explored.

Aims: To examine what young people in Early Intervention Services (EIS) think about psychological therapies for psychosis.

Method: Thirty participants were recruited from EIS across five NHS trusts to examine young people's beliefs about psychological therapy.

Results: Four distinct factors, or sets of beliefs, about therapy emerged: (1) Therapy is helpful and gives hope for the future; (2) Therapy is just talking, people need medication; (3) Therapy is useful but stigmatising; (4) Therapy is better than medication. Positive views towards different aspects of therapy were present in all four accounts. Other important issues were raised, including concerns about stigma and opposing beliefs about medication.

Conclusions: These four factors provide useful insights into young people's beliefs about psychological therapy. Individuals' beliefs and expectations should be recognised and explored in order to promote greater engagement in and better outcomes from therapy. Declaration of interest: None

Keywords: Therapy; beliefs; psychosis; Q-methodology; service users 


\section{Introduction}

The National Institute for Health and Care Excellence (NICE) guidelines (2011; 2014) recognise psychological interventions as vital elements of treatment for psychosis yet their implementation within services is often hampered by poor engagement and high attrition rates (Perivoliotis et al, 2010; Villeneuve, Potvin, Lesage \& Nicole, 2010). Medication adherence in psychosis has received considerable attention (e.g. Coldham, Addington \& Addington, 2002) but comparatively little research has explored factors associated with adherence to psychological therapy. Individuals' pre-existing beliefs about psychological therapy may impact on whether and how they engage with therapy (Hui et al, 2006; Lecomte et al 2008; Mutsatsa et al, 2003) and ambivalent attitudes may preclude engagement (Hazell et al, 2018; Ince et al, 2015). Beliefs and expectations can also influence individuals' experience of the therapeutic process and impact on outcome (Westra et al, 2010). A recent systematic review (Holding, Gregg \& Haddock, 2016) found that beliefs, attitudes, or expectations about therapy for psychosis have not been adequately explored. Research has tended to focus on individuals' therapy experience, including the process (what happens in therapy; how they are treated), outcomes (change, skills), and therapist characteristics. Relatively less data is available on the challenges of therapy and as such, findings are predominantly positive. Likewise, little information is available on people's expectations of therapy, and where studies have included questions about prior expectations, the questioning has largely taken place subsequent to completion of the therapy, which may introduce bias (Holding et al, 2016; Westra, Aviram, Barnes \& Angus, 2010). Moreover, the majority of data comes from people who have engaged with therapy, with very little from those who have dropped out or refused 
therapy altogether, and is therefore not representative of the views or beliefs of many who are eligible for psychosis services (Holding et al, 2016). To address these limitations we recruited participants with a varied therapy history and explored their beliefs and expectations about psychological therapy. We included people who had completed therapy, those who had declined therapy, those who had struggled to engage consistently in therapy, and those without prior experience of psychological interventions. Hence our study encompasses a broader range of therapy experiences than previous studies and highlights areas for exploration with clients before or during therapy in order to promote engagement and potentially improve outcomes (Ogrodniczuk, Joyce \& Piper, 2005; Westra et al, 2010).

Q methodology (Stephenson, 1953) was used as it aims to highlight and understand a diversity of viewpoints, including unheard or uncommon perspectives. Participants rank statements in relation to each other, which provides an overview of their viewpoint on the topic of interest (Stenner, Cooper \& Skevington, 2003). Q-methodology has been found acceptable for use in chronic and first episode psychosis populations (e.g. Jones, Guy \& Ormrod, 2003; Gregg, Haddock \& Barrowclough, 2009; Wood, Price, Morrison \& Haddock, 2013; Barr, Ormrod \& Dudley, 2015). It can be helpful when exploring complex concepts like beliefs, as it offers a broad range of accessible and acceptable responses, providing material for participants to reflect on and identify with (Dudley, et al, 2009). 


\section{Materials and Methods}

\section{Development of the $Q$ concourse}

The Q concourse for this study (the set of statements representing the range of beliefs about therapy) was derived from two main sources:

(1) Existing research literature on beliefs, expectations, or experiences of psychological therapy

(2) Semi-structured interviews with young people who have experienced symptoms of $\operatorname{psychosis}(n=11)$

The existing research literature

A systematic search of the literature was conducted using Ovid electronic database, including a combination of terms relating to psychological therapies; mental health, symptom or diagnostic profiles; and beliefs, experiences, or expectations. The search was not limited to psychosis since expectations or reasons for refusing or dropping out of therapy are lacking in psychosis research. Statements relevant to beliefs about therapy were extracted, including direct quotes or items from outcome measures or surveys. Only data from service users or people who had been offered therapy or were on a waiting list for therapy was considered; theoretical or mental health staff views were excluded. This process resulted in 27 articles from which 245 belief statements about therapy were extracted.

Interviews

A semi-structured interview exploring expectations and beliefs about therapy was administered to 11 people. All were White males in EIS with mean age of 28.82 
$(\mathrm{SD}=4.60)$ (range 21-36). Participants had recently taken part in a randomised controlled trial (RCT), the ReCAP Trial, which investigated the effectiveness of CBT combined with Motivational Interviewing (MiCBT) for young cannabis users with psychosis (Barrowclough et al, 2014). Four had been allocated to therapy (attending 1, 6, 17, and 22 sessions respectively) and seven had been allocated to treatment as usual. The schedule included questions about expectations of therapy and possible influences on these. Previous experiences of therapy and therapists, reasons for participating, declining and dropping out of therapy, including difficulties or challenges, were explored. Naïve participants were asked what they thought therapy might have been like. These interviews identified an additional 64 belief statements about therapy.

\section{Development of the $Q$ set}

The 309-item Q-concourse was reduced and refined in stages on the grounds of duplication and clarity, and to adjust language (see Stainton-Rogers, 1995) by the authors and a group of young people from a local mental health support group, aged 16-24. This resulted in a final Q-set of 64 statements. These were a mixture of general positive and negative beliefs about therapy, the setting or process, role expectations, perceived benefits (or lack of) including skills or improvement, medication, stigma, and other potential barriers.

\section{Other materials}

Additional information obtained from participants and their casenotes, included demographic details; psychological therapy history (mode, model and practitioner); brief substance use history and self-report symptomatology (Subjective Experiences of Psychosis Scale, SEPS, Haddock et al., 2011). The SEPS evaluates multi-dimensional 
experiences of psychosis. It contains 45 items, across 3 subscales, rated on a 5-point likert-type scale ranging from 1 (not at all) to 5 (very much). Subscales include: the positive and negative impact of psychotic experience on mental health and well-being, the positive and negative impact of support (such as treatment, support from friends or family) on psychotic experiences, and the severity of different dimensions of psychotic experiences (frequency, pleasantness) symptoms.

\section{Participants}

Participants were recruited from five EIS in Greater Manchester, Lancashire, Cheshire and Merseyside, UK, either as part of an exit interview following participation in an RCT or via referral from their EIS case manager. Participants were not required to have prior experience of psychological therapy to be eligible.

\section{Procedure}

The study was approved by an NHS research ethics committee (NRES North West: 08/H1015/82) and all participants gave informed consent. The first author and two research assistants administered the Q sort. Sixty-four numbered cards, each containing a single belief statement, were shuffled and given to participants for sorting onto an A1sized grid in accordance with their individual perspective. Participants were required to rank the cards from most agree to most disagree (figure 1.)

\section{[INSERT FIGURE 1 NEAR HERE]}

Recommended procedures for breaking the sorting task down into provisional ranking categories (agree, disagree, neutral) were followed (see Watts \& Stenner, 2012). 
Participants were encouraged to ask questions and make changes as required. Final card positions were recorded by the researcher and a brief post-Q interview was conducted to explore participants' ranking choices and obtain opinions of the task and topic. The Qsort and post-Q interview were digitally recorded to aid interpretation of factors.

\title{
Data analysis
}

Q-data were analysed using a dedicated software package (PQ Method v.2.35, Schmolck, 2002). Principle Components Analysis (PCA) with varimax rotation was employed, maximising the amount of variance explained by extracted factors. In $\mathrm{Q}$ methodology, factors demonstrate the relationship between participants, not between items, with each factor comprising participants who sorted statements similarly. Significant loading Q-sorts were identified to define each factor, which were then merged to produce factor arrays. These represent the best estimate or average of the Q-sorts for each factor. Factor arrays were interpreted in order to develop a summarizing account of the viewpoint being expressed by each factor (Watts and Stenner, 2005; Stainton-Rogers, 1995).

\section{Results}

Participants' demographic data, for the total sample and by individual factor, are reported in Table 1.

\section{[INSERT TABLE 1 NEAR HERE]}

\author{
PCA resulted in a four-factor solution, on which 24 of the Sorts loaded, \\ explaining $68 \%$ of the variance. Sixteen participants loaded on factor 1 (explaining 33\%
}


of the variance), three loaded on factor $2(8 \%)$, one on factor $3(12 \%)$, and four on factor $4(15 \%)$. Six sorts were excluded from the factor arrays (Table 2 ) as they loaded on multiple factors, and were therefore not considered in interpretation of factors below.

\section{[INSERT TABLE 2 NEAR HERE]}

\section{Interpretation of $Q$ Sorts}

For brevity, only summary interpretations are presented here. Full summaries are available from the corresponding author.

Factor 1 - "Therapy is helpful and gives hope for the future"

This factor included people who appeared to have globally strong positive views about psychological therapy, including its ability to bring about change, the process, and the people that deliver therapy. People who loaded on this factor believed that therapy 'provides support' $(+6)$, 'is helpful' $(+5)$, 'provides hope for the future' $(+4)$ and strongly disagreed that it was 'a waste of time' (-6). They appeared to believe that therapy provided a unique service, as they disagreed that therapy 'is not necessary, someone else could support a person's needs instead' $(-3)$. People in this factor appeared to be generally ambivalent about medication as an adjunct to therapy (e.g. therapy 'is more helpful than taking tablets', 0) as well as other ways of getting help (therapy 'is not the only way for people to get help', 0) but strongly disagreed that medication is a replacement for therapy: Therapy 'is just talking, people need medication instead' (-6).

People in this group believed most strongly that therapy 'can help people make changes in their lives' $(+5)$, and disagreed that it 'only provides short term solutions' $(-3)$. 
They rated a number of change or positive outcome statements higher than people on other factors, for example: 'helps people cope with their experiences' $(+3)$ and 'helps people overcome stressful life events' $(+3)$.

They also appeared to have very positive beliefs about the process or setting in which therapy takes place, including how they would be treated and having a personal sense of control. They were the only group to disagree that therapy 'is guided by a therapist, not by the person' (-2) and strongly disagreed that it 'makes people make changes they don't want to make' (-5). For people in this group, therapy seemed to be a non-judgemental and non-stigmatising environment, which facilitates open and honest discussion, which may not be possible with family and friends. For example, they believed that therapy 'accepts people as they are without judging them' $(+6)$ and 'is somewhere people can talk about problems without being ashamed' $(+5)$.

\section{Factor 2 - "Therapy is just talking, people need medication"}

These three participants had strong views about the importance of medication. In contrast to factor 1 , they did not believe that therapy could be effective without other things in place, such as medication. Therapy was viewed as 'not the only way for people to get help' $(+5)$ and they disagreed that it 'is more helpful than taking tablets' $(-5)$. They believed that therapy 'is just talking, people need medication instead' $(+5)$ and 'is only helpful if the person is taking medication as well' $(+4)$. They were the only group to endorse that therapy 'is only for people with something wrong with them' $(+2)$

While medication seemed to be viewed as a necessity, they still held some positive general views about psychological therapy. They disagreed that therapy 'makes people's problems worse' (-6) and believed it 'helpful' (+6). They believed therapy is 
somewhere to: 'be listened to' $(+6)$, 'get self-understanding or insight' $(+4)$ and 'talk to someone who understands' (+3).

Unlike factor 1, they did not endorse many positive specific benefits to therapy and seemed to lack belief or hope that therapy could bring about change. For example, they disagreed that therapy 'can help people make changes in their lives' (-4) or 'helps people feel less distressed' (-5). They were uncertain about therapy in general, viewing it as 'an unknown which puts people off from trying it' $(+4)$.

Factor 3 - "Therapy is useful but stigmatising"

This participant expressed mixed views about therapy. He disagreed that therapy 'is somewhere people can talk about problems without being ashamed' (-3) and 'accepts people as they are without judging them' (-5), possibly leading him to disagree that therapy 'is somewhere people can talk honestly' (-6) and 'is somewhere people can talk about things that they are not comfortable telling family or friends' (-4). Moreover, he believed that therapy 'is something that people are too embarrassed to attend because of what other people would think' $(+4)$ and expressed the strongest concern compared to other factors that therapy 'makes people talk about things that will play on their mind later' $(+4)$. At the same time, he did have some positive beliefs about therapy: He agreed that therapy 'helps people understand the impact of the past on what is happening now' $(+6)$, 'helps people feel more confident in social situations' $(+6)$, and 'helps people get control over their problems' (+4).

\section{Factor 4 - "Therapy is better than medication"}

People in this group were the most strongly opposed to medication, disagreeing that therapy 'is only helpful if the person is taking medication as well' (-6) and 'is just 
talking, people need medication instead' $(-4)$. However, they also appeared to be uncertain or ambivalent about whether therapy 'is helpful' (0) and could facilitate change in their lives but still believed it 'is more helpful than taking tablets' $(+3)$. They held the strongest positive beliefs about the therapy setting and how they would be treated. They expressed strong consistent beliefs that therapy 'is somewhere to be listened to' $(+6)$, 'is somewhere people are treated as individuals, not as an illness' $(+5)$, 'accepts people as they are without judging them' $(+4)$, 'is somewhere people can talk about things that they are not comfortable telling family or friends' $(+6)$, and 'is a respectful relationship between equals' $(+4)$. This could in turn influence beliefs about how they could be in sessions, endorsing that therapy 'is somewhere people can talk honestly' $(+5)$ and 'is somewhere people can talk about problems without being ashamed $(+3)$.

\section{Discussion}

This study aimed to explore young people's beliefs about psychological therapy for psychosis using Q-methodology and four distinct factors were identified. The results suggest that young people in EIS have complex and multi-faceted beliefs about different aspects of psychological therapy, including the process, normalisation and stigma, outcomes, and the people who deliver it. All participants had some level of positive belief about psychological therapy, albeit potentially for different reasons. In addition, interesting views about medication and usefulness in relation to therapy also emerged.

Factor 1/Therapy is helpful and gives hope for the future consisted of people who presented a strong case for psychological therapy. It represents just over half of the entire study sample. These views are in line with the current research available on 
peoples' beliefs about therapy for psychosis (Holding et al, 2016). They expressed positive views about all elements of the therapeutic process and believed that therapy played a unique role in supporting people in a non-stigmatising environment, in order to facilitate change and hope for the future.

Factor 2/Therapy is just talking; people need medication illustrates a more traditional view about therapy and medication. In sharp contrast to other groups they had strong views about the importance of medication being the only way to improve. They did not agree that therapy could accomplish change. It is possible that this group were less symptomatic and this view arose because they may differentiate themselves from 'less well' peers. However, they reported the lowest average score on severity of negative dimensions of psychosis and did not appear to differ from other groups with regard to frequency of psychotic symptoms. They are possibly more likely to endorse a medical or biological model explanation of the aetiology of psychosis and may feel that their difficulties are not psychological. They may have had these preconceptions before entering services, or may have been told that therapy is not helpful without medication for psychosis. This could be due to staff influences, who also often hold these views (Prytys et al, 2011) or may be attributable to the view that symptoms (such as voices) may get in the way of therapy (Hazell et al, 2017). Although there are arguments for psychological therapy for psychosis without medication (Morrison et al, 2012; 2018) current treatment guidelines endorse antipsychotic medication (NICE, 2014) and this is reflected in clinical practice.

Factor 3/Therapy is useful but stigmatising was the only one to voice a strong belief or worry that therapy could be a stigmatising, shaming, or judgemental experience, 
both because of the therapy process and because of what others might think. Some people might avoid mental health settings or treatment because they may be viewed as stigmatising, particularly if they have concerns about acceptance from peers and avoiding rejection (Gaebel et al, 2006). Young people with this view may be deterred from seeking help early which could negatively impact the duration of untreated psychosis and illness course. It must be noted that this factor was determined by one person's Q-sort. There is debate about whether factors of one should be retained or not, however support for this practice is available from two noteworthy Q-researchers: Brown (1980) and Stephenson (1964) posit that solitary or unique viewpoints can be significant, and as they may not constitute the 'norm', will not load onto other factors. These beliefs are certainly significant as stigma and social exclusion are common in the experience of psychosis (NICE, 2014).

Factor 4/Therapy is better than medication expressed the strongest beliefs against medication and about the way people are treated in therapy. It is interesting that these beliefs were held alongside ambivalence about the helpfulness of therapy, indicating uncertainty about anything being able to help.

\section{Strengths and limitations}

This study incorporated service user input at all stages of the research: they helped generate items for the Q-concourse, provided input on final item inclusion, terminology and design of the Q-set, and piloted the final materials. Factor summaries were reviewed and confirmed in line with a service user perspective with a Service User Development Worker, a former EIS user. This level of involvement throughout the study ensured that the content and materials were meaningful, representative and relevant from 
a service user perspective. While the development of the Q-set was performed systematically to be as inclusive as possible, it may not have included every belief. However, none of the participants suggested additional items for inclusion in the Q-set and they judged it to be comprehensive and representative of their beliefs.

The recruited sample may not be representative of EIS (or psychosis) populations and this research encountered similar limitations of previous studies in terms of sample characteristics. Participants were predominantly White males, who were engaged with services, and almost all had experiences of therapy. However, not all had completed or had helpful experiences of therapy, and described terminating therapy prematurely, which is in contrast to the majority of previous research exploring therapy experiences (Holding et al, 2016) and a further strength of this study.

Overall, a positive story has been told, however, this may be in part due to limitations in recruitment. More than two thirds of the sample had participated in an RCT of psychological therapy (the ReCAP trial, Barrowclough et al, 2014) and may be more likely to have held positive beliefs about therapy. Strategic sampling is acceptable and recommended in Q-research (Watts \& Stenner, 2012) and case managers were encouraged to identify Black and Minority Ethnic (BME) services users or people who have refused, dropped out, or may have negative views about therapy. Recruitment of these individuals proved difficult.

More than two thirds of participants met criteria for substance abuse at some point in the last 18 months (inclusion criteria for participation in the RCT). People with coexisting substance use may have additional needs and complexities compared to other service users with psychosis, and it is possible their beliefs may not be representative of 
EIS users as a whole (Cleary et al, 2008; NICE, 2011). However, substance use and abuse rates are high in FEP populations (Lambert et al, 2005), and it is important to consider beliefs about substance use as well when working with this population (Gregg et al, 2009). Nonetheless, this is the first study to explore beliefs about therapy from such a broad range of participants.

\section{Clinical implications}

Clinicians need to better understand service user concerns about therapy, as managing expectations and beliefs before therapy commences may facilitate better outcomes (Ogrodniczuk et al, 2005). Q methodology could be a useful tool for professionals across disciplines to assess expectations and beliefs for further exploration (Jones et al, 2003). Post sort interviews revealed that participants found Q less scrutinising and more enjoyable than traditional interview or questionnaire techniques. Negative beliefs are included in the Q-set, suggesting they are common and appropriate beliefs to hold, which may elicit more balanced accounts of beliefs.

Q can also facilitate useful content for discussions. These beliefs may be difficult to access, particularly with no prior experience of therapy. However, all people are likely to have beliefs about therapy, influenced by a number of sources, including media portrayals, which could lead to the development of faulty or unhelpful beliefs about therapy (Grazebrook et al, 2004). If these negative appraisals of therapy, such as fears or misconceptions about therapists, the process, and stigma go unexplored, and accurate explanations are not promoted, people may miss out on an important element of treatment. Clinicians should be mindful not to make assumptions about therapy beliefs based on previous therapy adherence. Service users can hold positive beliefs about 
therapy, despite finding it difficult to engage with. Conversations about potential barriers, including negative expectations, could help develop future care planning options, which may improve the chance for the service user to participate more fully in therapy in the future.

Previous research has identified potential barriers to therapy, such as concerns about cultural differences, confidentiality, implications of confidentiality breaches, therapy making symptoms worse, and not having a choice in therapy (Holding et al, 2016; Rathod, et al 2010; Westra et al, 2010). Few participants in this research had these concerns, possibly because the majority had previously taken part in an RCT, and this should remain a focus when discussing therapy.

An awareness of these beliefs may lead to different approaches or options being made available to service users. NICE guidelines for psychosis (2014) make recommendations for the use of peer support involving a trained peer support worker who has recovered from psychosis to provide advice and information. Meeting people who have recovered from psychosis, potentially with the help of therapy, could be both normalising and inspiring for people who may be hopeless, unsure about therapy or have concerns about stigmatisation. Voluntary support groups (such as the Hearing Voices Network) or group therapy approaches may also be particularly beneficial for those who feel isolated or stigmatised (Goodliffe et al, 2010; Newton et al, 2007; Romme \& Escher, 2000). 


\section{Future research}

The impact of therapy beliefs in psychosis has yet to be seen. Future research could explore the impact of beliefs about therapy on engagement and attrition, outcomes, and satisfaction. Studies would also benefit from alternative recruitment strategies to promote engagement for underrepresented groups in both research and mental health services, such as people who do not engage and BME groups. For some BME groups in particular, therapy dropout rates are higher and outcomes are poorer (Rathod et al, 2005; Turkington et al, 2002) and their beliefs about therapy may be less positive. Exploring beliefs in under-represented groups may help us to understand the potential impact of cultural beliefs on engagement with therapy. 


\section{References}

Barr, K., Ormrod, J., \& Dudley, R. (2015). An exploration of what service users value about early intervention in psychosis services. Psychology and Psychotherapy: Theory, Research and Practice, 88(4), 468-480. doi: http://dx.doi.org/10.1111/papt.12051

Barrowclough, C., Marshall, M., Gregg, L., Fitzsimmons, M., Tomenson, B., Warbutton, J., \& Lobban, F. (2014). A phase-specific psychological therapy for people with problematic cannabis use following a first episode of psychosis: a randomized controlled trial. Psychological medicine, 44(13), 2749-61. doi: http://dx.doi.org/10.1017/S0033291714000208

Brown, S. R. (1980). Political subjectivity. New Haven: Yale University Press.

Cleary, M., Hunt, G., Matheson, S., Siegfried, N., \& Walter, G. (2008). Psychosocial interventions for people with both severe mental illness and substance misuse. Cochrane Database of Systematic Reviews(1), CD001088. doi: http://dx.doi.org/10.1002/14651858.CD001088.pub2

Coldham, E. L., Addington, J., \& Addington, D. (2002). Medication adherence of individuals with a first episode of psychosis. Acta Psychiatrica Scandinavica, 106(4), 286-290.

Dudley, R., Siitarinen, J., James, I., \& Dodgson, G. (2009). What do people with psychosis think caused their psychosis? A Q methodology study. Behavioural and Cognitive Psychotherapy, 37(1), 11-24. doi: http://dx.doi.org/10.1017/S1352465808004955

Gaebel, W., Zaske, H., \& Baumann, A. E. (2006). The relationship between mental illness severity and stigma. Acta Psychiatrica Scandinavica, Supplementum(429), 41-45.

Goodliffe, L., Hayward, M., Brown, D., Turton, W., \& Dannahy, L. (2010). Group person-based cognitive therapy for distressing voices: views from the hearers. Psychotherapy Research, 20(4), 447-461. doi: http://dx.doi.org/10.1080/10503301003671305

Grazebrook, K. A., Siddle, R., Leadley, K., Everitt, J., Benn, A., Haddock, G., . . Tarrier, N. (2004). First Episode Psychosis: Two Cases to Illustrate the Role of Cognitive Behaviour Therapy in Making Sense of Unusual Experiences. Behavioural and Cognitive Psychotherapy, 32(3), 331-345. doi: http://dx.doi.org/10.1017/S1352465804001390

Gregg, L., Haddock, G., \& Barrowclough, C. (2009). Self-reported reasons for substance use in schizophrenia: a Q-methodological study. Mental Health and Substance Use: Dual Diagnosis, 2, 24-39.

Haddock, G., Wood, L., Watts, R., Dunn, G., Morrison, A. P., \& Price, J. (2011). The Subjective Experiences of Psychosis scale (SEPS): Psychometric evaluation of a scale to assess outcome in psychosis. Schizophrenia Research, 133(1-3), 244-249. doi: http://dx.doi.org/10.1016/j.schres.2011.09.023 

Hayward, M. (2018). Understanding the barriers to accessing symptom-specific Cognitive Behavior Therapy (CBT) for distressing voices: Reflecting on and extending the lessons learnt from the CBT for psychosis literature. Frontiers in psychology, 9: 727 https://doi.org/10.3389/fpsyg.2018.00727

Hazell, C. M., Strauss, C., Cavanagh, K., \& Hayward, M. (2017). Barriers to disseminating brief CBT for voices from a lived experience and clinician perspective. PloS one, 12 (6) https://doi.org/10.1371/journal.pone.0178715

Holding, J. C., Gregg, L., \& Haddock, G. (2016). Individual's experiences and opinions of psychological therapies for psychosis: a narrative synthesis. Clinical Psychology Review, 43, 142-161. doi: http://dx.doi.org/10.1016/j.cpr.2015.10.004

Hui, C. L., Chen, E. Y., Kan, C. S., Yip, K. C., Law, C. W., \& Chiu, C. P. (2006). Detection of non-adherent behaviour in early psychosis. Australian \& New Zealand Journal of Psychiatry, 40(5), 446-451.

Ince, P. Haddock, G. \& Tai, S. (2015). A systematic review of the implementation of recommended psychological interventions for schizophrenia: rates, barriers, and improvement strategies. Psychology and Psychotherapy: Theory, Research and Practice, 89, 324-350 https://doi.org/10.1111/papt.12084

Jones, S., Guy, A., \& Ormrod, J. A. (2003). A Q-methodological study of hearing voices: a preliminary exploration of voice hearers' understanding of their experiences. Psychology \& Psychotherapy: Theory, Research \& Practice, 76(Pt 2), 189-209.

Lambert, M., Conus, P., Lubman, D. I., Wade, D., Yuen, H., Moritz, S., . . . Schimmelmann, B. G. (2005). The impact of substance use disorders on clinical outcome in 643 patients with first-episode psychosis. Acta Psychiatrica Scandinavica, 112(2), 141-148.

Lecomte, T., Spidel, A., Leclerc, C., MacEwan, G., Greaves, C., \& Bentall, R. P. (2008). Predictors and profiles of treatment non-adherence and engagement in services problems in early psychosis. Schizophrenia Research, 102(1-3), 295-302. doi: http://dx.doi.org/10.1016/j.schres.2008.01.024

Morrison, A.P., Law, H., Carter, L. Sellers, R., Emsley, R.. Pyle, M. et al (2018). Antipsychotic drugs versus cognitive behavioural therapy versus a combination of both in people with psychosis: a randomised controlled pilot and feasibility study. The Lancet Psychiatry, 5 (5), 411-423. https://doi.org/10.1016/S2215-0366(18)30096-8

Morrison, A. P., Turkington, D., Wardle, M., Spencer, H., Barratt, S., Dudley, R., . . Hutton, P. (2012). A preliminary exploration of predictors of outcome and cognitive mechanisms of change in cognitive behaviour therapy for psychosis in people not taking antipsychotic 
medication. Behaviour Research and Therapy, 50(2), 163-0167. doi: http://dx.doi.org/10.1016/j.brat.2011.12.001

Mutsatsa, S. H., Joyce, E. M., Hutton, S. B., Webb, E., Gibbins, H., Paul, S., \& Barnes, T. R. (2003). Clinical correlates of early medication adherence: West London first episode schizophrenia study. Acta Psychiatrica Scandinavica, 108(6), 439-446.

Newton, E., Larkin, M., Melhuish, R., \& Wykes, T. (2007). More than just a place to talk: Young people's experiences of group psychological therapy as an early intervention for auditory hallucinations. Psychology and Psychotherapy: Theory, Research and Practice, 80(1), 127-149. doi: http://dx.doi.org/10.1348/147608306X110148

National Institute for Health and Clinical Excellence (2011). Psychosis with coexisting substance misuse: Assessment and management in adults and young people 120 London: National Institute for Health and Clinical Excellence.

National Institute for Health and Clinical Excellence (2014). Psychosis and schizophrenia in adults: treatment and management CG178. London: National Institute for Health and Clinical Excellence.

Ogrodniczuk, J. S., Joyce, A. S., \& Piper, W. E. (2005). Strategies for Reducing Patient-Initiated Premature Termination of Psychotherapy. Harvard Review of Psychiatry, 13(2), 57-70. doi: http://dx.doi.org/10.1080/10673220590956429

Rathod, S., Kingdon, D., Phiri, P., \& Gobbi, M. (2010). Developing culturally sensitive cognitive behaviour therapy for psychosis for ethnic minority patients by exploration and incorporation of service users' and health professionals' views and opinions. Behavioural and Cognitive Psychotherapy, 38(5), 511-533.

Rathod, S., Kingdon, D., Smith, P., \& Turkington, D. (2005). Insight into schizophrenia: the effects of cognitive behavioural therapy on the components of insight and association with sociodemographics--data on a previously published randomised controlled trial. Schizophrenia Research, 74(2-3), 211-219.

Romme, M., \& Escher, S. (2000). Making Sense of Voices: A Guide for Mental Health Professionals Working with Voice-Hearers: Mind Publications

Schmolck, P. (2002). PQ Method. Retrieved from http://schmolck.userweb.mwn.de/qmethod/downpqwin.htm

Stainton-Rogers, R. (1995). Q methodology. In J. A. Smith \& L. Van Langenhove (Eds.), Rethinking methods in psychology. London: Sage.

Stenner, P. H., Cooper, D., \& Skevington, S. M. (2003). Putting the Q into quality of life; the identification of subjective constructions of health-related quality of life using $Q$ 
methodology. Social Science \& Medicine, 57(11), 2161-2172.

Stephenson, W. (1953). The study of behavior: Q-technique and its methodolgoy. Chicago: University of Chicago Press.

Stephenson, W. (1964). Application of the Thompson schema to the current controversy over Cuba. The Psychological Record, 14(3), 275-290.

Turkington, D., Kingdon, D., \& Turner, T. (2002). Effectiveness of a brief cognitive-behavioural therapy intervention in the treatment of schizophrenia. The British Journal of Psychiatry, 180(6), 523-527. doi: http://dx.doi.org/10.1192/bjp.180.6.523

Villeneuve, K., Potvin, S., Lesage, A., \& Nicole, L. (2010). Meta-analysis of rates of drop-out from psychosocial treatment among persons with schizophrenia spectrum disorder. Schizophrenia Research, 121(1-3), 266-270. doi: http://dx.doi.org/10.1016/j.schres.2010.04.003

Watts, S., \& Stenner, P. (2005). Doing Q methodology: Theory, method and interpretation. Qualitative Research in Psychology, 2(1), 67-91.

Watts, S., \& Stenner, P. (2012). Doing Q methodological research: theory, method and interpretations. London: Sage.

Westra, H. A., Aviram, A., Barnes, M., \& Angus, L. (2010). Therapy was not what I expected: a preliminary qualitative analysis of concordance between client expectations and experience of cognitive-behavioural therapy. Psychotherapy Research, 20(4), 436-446. doi: http://dx.doi.org/10.1080/10503301003657395

Wood, L., Price, J., Morrision, A., \& Haddock, G. (2013). Exploring service users perceptions of recovery from psychosis: A Q-methodological approach. Psychology \& Psychotherapy: Theory, Research \& Practice, 86(3), 245-261. doi: http://dx.doi.org/10.1111/j.2044$\underline{8341.2011 .02059 . x}$ 
Table 1. Participant Characteristics.

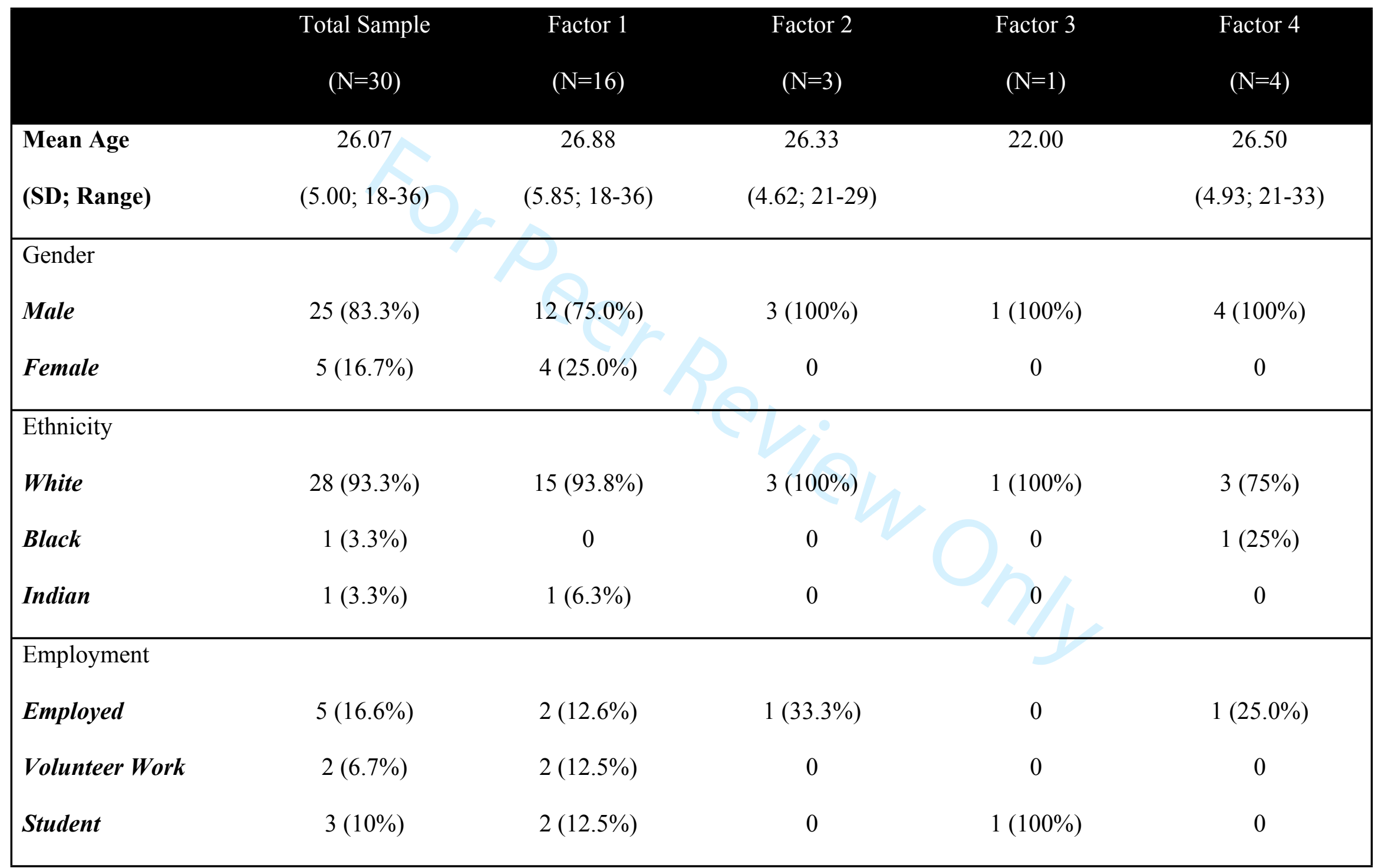




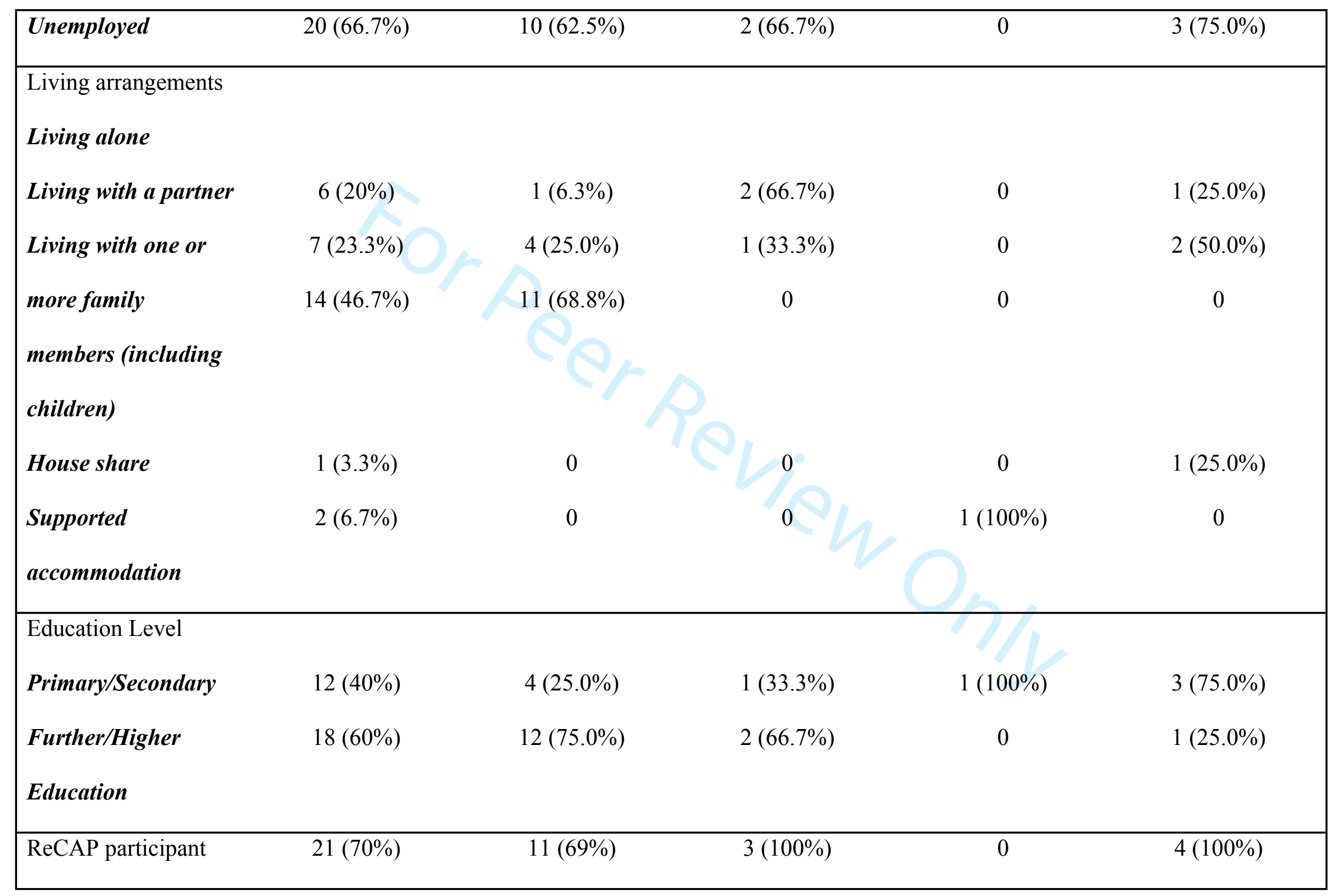




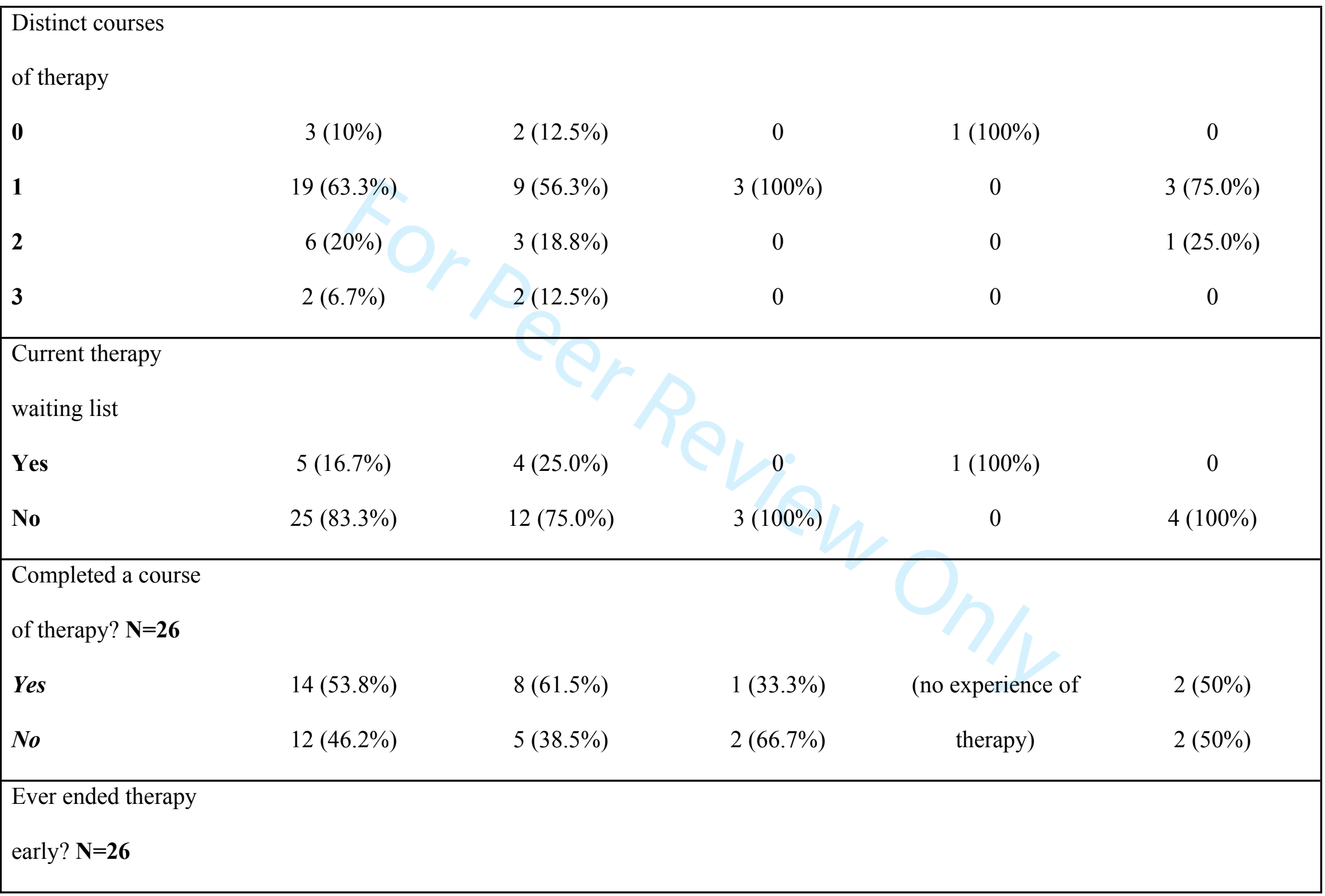




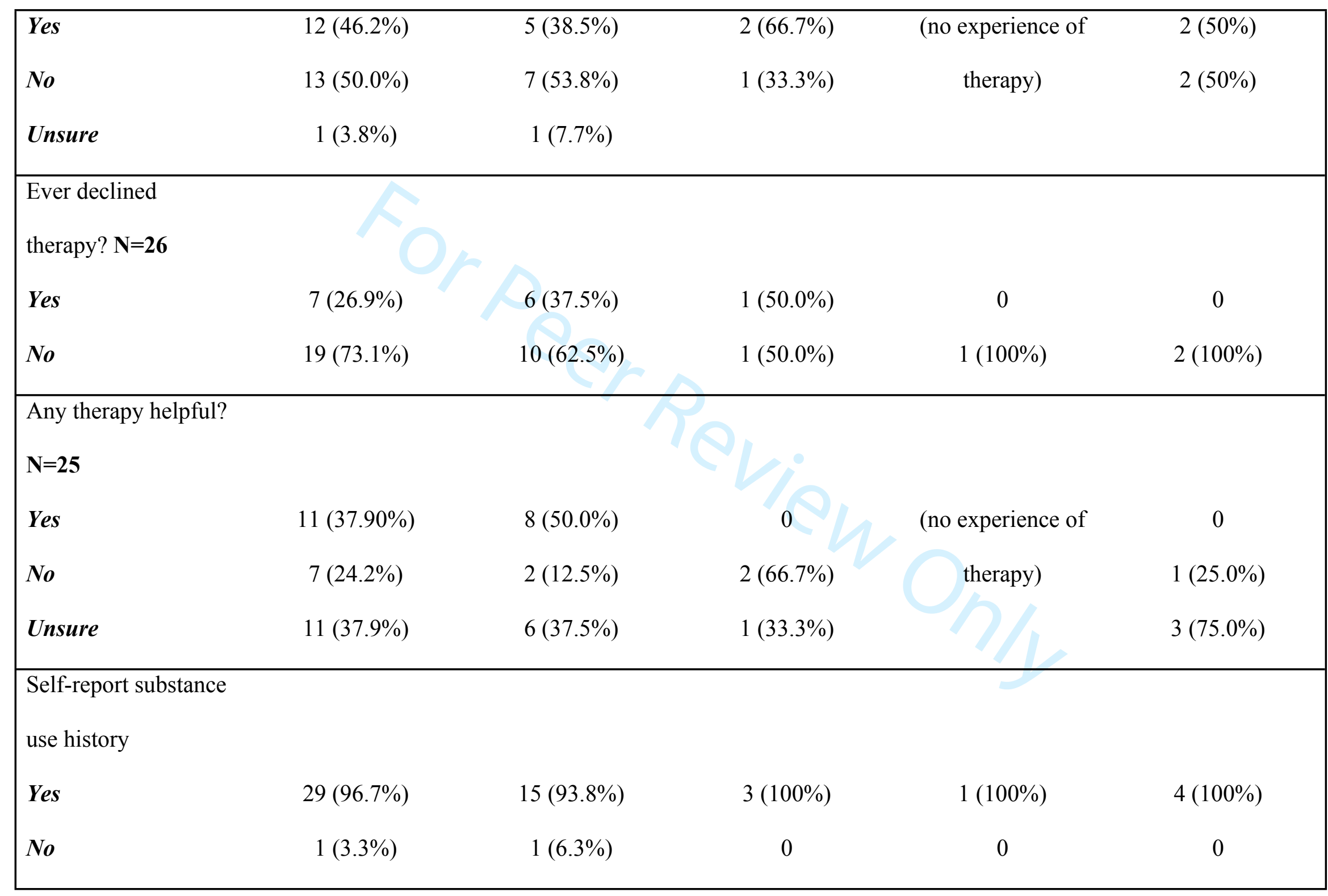




\begin{tabular}{|c|c|c|c|c|c|}
\hline \multicolumn{6}{|l|}{$\begin{array}{l}\text { Self-report current } \\
\text { symptoms of } \\
\text { psychosis }\end{array}$} \\
\hline Yes & $19(63.3 \%)$ & $9(56.3 \%)$ & $2(66.7 \%)$ & $1(100 \%)$ & $4(100 \%)$ \\
\hline No & $11(36.7 \%)$ & $7(43.8 \%)$ & $1(33.3 \%)$ & 0 & 0 \\
\hline $\begin{array}{l}\text { SEPS - frequency of } \\
\text { psychotic experiences } \\
\text { in last week }\end{array}$ & & & & & \\
\hline Not at all & $10(33.3 \%)$ & $7(43.8 \%)$ & $1(33.3 \%)$ & & 0 \\
\hline A little & $4(13.3 \%)$ & $2(12.5 \%)$ & $1(33.3 \%)$ & --- & 0 \\
\hline Moderately & $5(16.7 \%)$ & 0 & 0 & & $3(75.0 \%)$ \\
\hline Quite a lot & $10(33.3 \%)$ & $7(43.8 \%)$ & $1(33.3 \%)$ & & $1(25.0 \%)$ \\
\hline Mean SEPS Positive & 50.37 & 50.37 & 42.33 & 78.00 & 56.75 \\
\hline $\begin{array}{l}\text { Impact of Experience } \\
\text { (SD; Range) }\end{array}$ & $(22.02 ; 29-109)$ & $(21.49 ; 29-109)$ & $(19.73 ; 29-65)$ & & $(20.19 ; 31-78)$ \\
\hline
\end{tabular}




\begin{tabular}{|c|c|c|c|c|c|}
\hline $\begin{array}{l}\text { Mean SEPS Negative } \\
\text { Impact of Experience } \\
\text { (SD; Range) }\end{array}$ & $\begin{array}{c}65.17 \\
(30.93 ; 29-142)\end{array}$ & $\begin{array}{c}70.63 \\
(34.63 ; 29-142)\end{array}$ & $\begin{array}{c}64 \\
(31.19 ; 31-93)\end{array}$ & 33.00 & $\begin{array}{c}70.50 \\
(32.88 ; 31-109)\end{array}$ \\
\hline $\begin{array}{l}\text { Mean SEPS Positive } \\
\text { Impact of Support } \\
\text { (SD; Range) }\end{array}$ & $\begin{array}{c}12.69 \\
(5.12 ; 5-23)\end{array}$ & $\begin{array}{c}13.81 \\
(4.85 ; 5-23)\end{array}$ & $\begin{array}{c}11.33 \\
(8.51 ; 5-21)\end{array}$ & --- & $\begin{array}{c}9.25 \\
(2.75 ; 6-12)\end{array}$ \\
\hline $\begin{array}{l}\text { Mean SEPS Negative } \\
\text { Impact of Support } \\
\mathbf{N}=\mathbf{2 9} \\
\text { (SD; Range) }\end{array}$ & $\begin{array}{c}7.10 \\
(3.38 ; 2-15)\end{array}$ & $\begin{array}{c}7.00 \\
(3.95 ; 2-15)\end{array}$ & $\begin{array}{c}5.00 \\
(.00 ; 5-5)\end{array}$ & --- & $\begin{array}{c}8.75 \\
(2.22 ; 7-12)\end{array}$ \\
\hline $\begin{array}{l}\text { Mean SEPS Positive } \\
\text { Dimensions of } \\
\text { Psychosis } \\
\text { Experiences } \\
\mathbf{N}=\mathbf{2 9} \\
\text { (SD; Range) }\end{array}$ & $\begin{array}{c}4.03 \\
(1.90 ; 2-9)\end{array}$ & $\begin{array}{c}4.12 \\
(2.28 ; 2-9)\end{array}$ & $\begin{array}{c}4.00 \\
(1.00 ; 3-5)\end{array}$ & & $\begin{array}{c}4.25 \\
(.96 ; 3-5)\end{array}$ \\
\hline
\end{tabular}




\begin{tabular}{|c|c|c|c|c|c|}
\hline Mean SEPS Negative & 11.79 & 12.69 & 8.33 & --- & 11.25 \\
\hline Dimensions of & $(3.95 ; 5-19)$ & $(4.22 ; 5-19)$ & $(3.51 ; 5-12)$ & & $(2.87 ; 7-13)$ \\
\hline \multicolumn{6}{|l|}{ Psychosis } \\
\hline \multicolumn{6}{|l|}{ Experiences } \\
\hline $\mathrm{N}=\mathbf{2 9}$ & & & & & \\
\hline (SD; Range) & & & & & \\
\hline
\end{tabular}

SEPS $=$ Subjective Experiences of Psychosis Scale 
Table 2. Factor Arrays.

\begin{tabular}{|c|c|c|c|c|}
\hline Psychological therapy & Factor & Factor & Factor & Factor \\
\hline & 1 & 2 & 3 & 4 \\
\hline 1. Is a way of getting advice & +2 & +4 & +2 & +3 \\
\hline 2. Is guided by a therapist, not by the person & -2 & 0 & +3 & +3 \\
\hline 3. Is a respectful relationship between equals & +1 & +1 & -4 & +4 \\
\hline $\begin{array}{l}\text { 4. Gives choice in what people want to work } \\
\text { on }\end{array}$ & +1 & +1 & +5 & +3 \\
\hline $\begin{array}{l}\text { 5. Involves people putting the work in } \\
\text { themselves }\end{array}$ & 0 & 0 & +2 & -5 \\
\hline 6. Is helpful & +5 & +6 & +2 & 0 \\
\hline 7. Is useful for anyone & -1 & +2 & 0 & +2 \\
\hline 8. Can help people make changes in their lives & +5 & -4 & +4 & +1 \\
\hline 9. Is somewhere to be listened to & +3 & +6 & +3 & +6 \\
\hline 10. Provides support & +6 & +2 & +3 & +3 \\
\hline 11. Is somewhere people can talk honestly & +4 & +5 & -6 & +5 \\
\hline $\begin{array}{l}\text { 12. Is somewhere to talk to someone who } \\
\text { understands }\end{array}$ & & +3 & +5 & +1 \\
\hline $\begin{array}{l}\text { 13. Is somewhere people can talk about things } \\
\text { they are not comfortable telling family or } \\
\text { friends }\end{array}$ & +4 & +1 & -4 & +6 \\
\hline $\begin{array}{l}\text { 14. Is somewhere people can talk about } \\
\text { problems without being ashamed }\end{array}$ & +5 & +2 & -3 & +3 \\
\hline 15. Is somewhere people learn that their & +1 & +3 & +6 & +2 \\
\hline
\end{tabular}




\begin{tabular}{|c|c|c|c|c|}
\hline \multicolumn{2}{|l|}{ experiences have been experiences by others } & & & \\
\hline $\begin{array}{l}\text { 16. Accepts people as they are without judging } \\
\text { them }\end{array}$ & +6 & +1 & -5 & +4 \\
\hline $\begin{array}{l}\text { 17. Is somewhere people are treated as } \\
\text { individuals, not as an illness }\end{array}$ & +2 & +3 & 0 & +5 \\
\hline $\begin{array}{l}\text { 18. Is a way of getting regular contact with } \\
\text { someone }\end{array}$ & +1 & +3 & +5 & +2 \\
\hline 19. Is something to look forward to each week & 0 & -1 & +1 & -1 \\
\hline 20. Provides hope for the future & +4 & -3 & -2 & -1 \\
\hline $\begin{array}{l}\text { 21. Is somewhere to get self-understanding or } \\
\text { insight }\end{array}$ & +1 & +4 & -3 & +4 \\
\hline $\begin{array}{l}\text { 22. Helps people understand the impact of the } \\
\text { past on what is happening now }\end{array}$ & +2 & 0 & +6 & +4 \\
\hline 23. Helps people overcome stressful life events & +3 & 0 & 0 & +1 \\
\hline 24. Helps people get control over their problems & +2 & -2 & +4 & +1 \\
\hline 25. Helps people cope with their experiences & +3 & 0 & +2 & -3 \\
\hline 26. Helps people feel less distressed/frightened & +2 & -5 & -3 & 0 \\
\hline 27. Helps people feel more confident & +3 & -4 & +2 & -1 \\
\hline 28. Helps people to start doing more in their life & +2 & -4 & +2 & 0 \\
\hline $\begin{array}{l}\text { 29. Helps people improve in their personal } \\
\text { relationships }\end{array}$ & 0 & -1 & 0 & -2 \\
\hline $\begin{array}{l}\text { 30. Helps people feel more comfortable in } \\
\text { social situations }\end{array}$ & +1 & -3 & +6 & 0 \\
\hline 31. Helps people identify when they are & +3 & -2 & +1 & 0 \\
\hline
\end{tabular}




\begin{tabular}{|c|c|c|c|c|}
\hline \multicolumn{2}{|l|}{ becoming unwell } & & & \\
\hline 32. Is a waste of time & -6 & -2 & -2 & -2 \\
\hline 33. Is for people who are weak & -5 & -6 & -2 & -1 \\
\hline 34. Only provides short term solutions & -3 & +1 & -3 & -1 \\
\hline 35. Cannot solve every problem & 0 & +1 & -1 & +6 \\
\hline 36. Makes people's problems worse & -5 & -6 & -2 & -4 \\
\hline $\begin{array}{l}\text { 37. Makes people talk about things that will } \\
\text { play on their mind later }\end{array}$ & 0 & +2 & +4 & +1 \\
\hline $\begin{array}{l}\text { 38. Makes people make changes they don't want } \\
\text { to make }\end{array}$ & -5 & -4 & -5 & -2 \\
\hline 39. Does not fit in with people's religious beliefs & -2 & 0 & -1 & -4 \\
\hline $\begin{array}{l}\text { 40. Is something that people can get too } \\
\text { dependent on }\end{array}$ & -1 & -2 & -4 & -2 \\
\hline $\begin{array}{l}\text { 41. Makes people talk about embarrassing } \\
\text { things }\end{array}$ & -1 & 0 & -6 & -5 \\
\hline $\begin{array}{l}\text { 42. Makes people bring up things from the past, } \\
\text { that aren't relevant to their problems now }\end{array}$ & -3 & -3 & -1 & +2 \\
\hline 43. Is too much hard work & -2 & -1 & -2 & -6 \\
\hline 44. Is too complicated for people to understand & -3 & -3 & -1 & 0 \\
\hline 45. Is only for people who are good at talking & -4 & 0 & 0 & -1 \\
\hline $\begin{array}{l}\text { 46. Is an unknown, which puts people off from } \\
\text { trying it }\end{array}$ & -1 & +4 & -1 & +1 \\
\hline $\begin{array}{l}\text { 47. Is only for people with something wrong } \\
\text { with them }\end{array}$ & -1 & +2 & -2 & -3 \\
\hline
\end{tabular}




\begin{tabular}{|c|c|c|c|c|}
\hline 48. Is not the only way for people to get help & 0 & +5 & -6 & 0 \\
\hline 49. Takes too long & -2 & -1 & -1 & -2 \\
\hline 50. Is more helpful that taking tablets & 0 & -5 & 0 & +3 \\
\hline $\begin{array}{l}\text { 51. Is just talking, people need medication } \\
\text { instead }\end{array}$ & -6 & +5 & +1 & -4 \\
\hline $\begin{array}{l}\text { 52. Is only helpful if the person is taking } \\
\text { medication as well }\end{array}$ & -1 & +4 & +1 & -6 \\
\hline 53. Is private and confidential & +6 & +6 & +3 & +5 \\
\hline $\begin{array}{l}\text { 54. Is too much for people to commit to with the } \\
\text { other things going on in their lives }\end{array}$ & -1 & +2 & -3 & -2 \\
\hline $\begin{array}{l}\text { 55. Is difficult to attend because of travel or cost } \\
\text { to get there }\end{array}$ & -2 & -2 & -5 & -5 \\
\hline $\begin{array}{l}\text { 56. Is something people are too embarrassed to } \\
\text { attend because of what other people would } \\
\text { think }\end{array}$ & -2 & -2 & +4 & 0 \\
\hline $\begin{array}{l}\text { 57. Is something that people attend only if } \\
\text { others pressure them to do it }\end{array}$ & -4 & -6 & -1 & -3 \\
\hline $\begin{array}{l}\text { 58. Is not necessary, someone else could support } \\
\text { a person's needs instead }\end{array}$ & -3 & -1 & +1 & -3 \\
\hline $\begin{array}{l}\text { 59. Is offered by therapists that people cannot } \\
\text { relate to }\end{array}$ & -4 & -3 & 0 & +1 \\
\hline $\begin{array}{l}\text { 60. Is offered by people who don't understand } \\
\text { different religions or cultures }\end{array}$ & -3 & -1 & -4 & -4 \\
\hline 61. Is offered by therapists that don't care about & -4 & -5 & 0 & -3 \\
\hline
\end{tabular}




\begin{tabular}{|c|c|c|c|c|}
\hline the people they see & & & & \\
\hline $\begin{array}{l}\text { 62. Is offered by people who just sit and listen, } \\
\text { and don't offer advice }\end{array}$ & -6 & -1 & +1 & -6 \\
\hline $\begin{array}{l}\text { 63. Is offered by therapists who are easy to talk } \\
\text { to }\end{array}$ & 0 & +1 & +1 & -1 \\
\hline 64. Is offered by people who want to help others & +1 & +3 & +3 & +2 \\
\hline
\end{tabular}




\title{
Young people's beliefs about psychological therapy for psychosis:
} A Q-methodological study

\author{
Joanne C. Holding ${ }^{1}$, Gillian Haddock ${ }^{2}$ and Lynsey Gregg ${ }^{2 *}$ \\ ${ }^{1}$ Lancashire Care NHS Foundation Trust, Lancashire, UK \\ ${ }^{2}$ School of Health Sciences, The University of Manchester, Manchester, UK \\ * Corresponding author: Lynsey Gregg, Division of Psychology and Mental Health, \\ School of Health Sciences, Faculty of Biology, Medicine and Health, The University of \\ Manchester, Manchester Academic Health Science Centre, Zochonis Building, \\ Brunswick Street, Manchester M13 9PL, England, UK. Email address: \\ lynsey.gregg@manchester.ac.uk. Telephone: 0044-161-3060400.
}

Word count: 3993 


\section{Abstract}

Background: The evidence base for the use of psychological therapies in the treatment of psychosis is growing, however engagement can be difficult and outcomes are variable. Beliefs, attitudes and expectations may have an important influence on whether individuals engage with therapy and on clinical outcomes, however, these beliefs have not been adequately explored.

Aims: To examine what young people in Early Intervention Services (EIS) think about psychological therapies for psychosis.

Method: Thirty participants were recruited from EIS across five NHS trusts to examine young people's beliefs about psychological therapy.

Results: Four distinct factors, or sets of beliefs, about therapy emerged: (1) Therapy is helpful and gives hope for the future; (2) Therapy is just talking, people need medication; (3) Therapy is useful but stigmatising; (4) Therapy is better than medication. Positive views towards different aspects of therapy were present in all four accounts. Other important issues were raised, including concerns about stigma and opposing beliefs about medication.

Conclusions: These four factors provide useful insights into young people's beliefs about psychological therapy. Individuals' beliefs and expectations should be recognised and explored in order to promote greater engagement in and better outcomes from therapy. Declaration of interest: None

Keywords: Therapy; beliefs; psychosis; Q-methodology; service users 


\section{Introduction}

The National Institute for Health and Care Excellence (NICE) guidelines (2011; 2014) recognise psychological interventions as vital elements of treatment for psychosis yet their implementation within services is often hampered by poor engagement and high attrition rates (Perivoliotis et al, 2010; Villeneuve, Potvin, Lesage \& Nicole, 2010). Medication adherence in psychosis has received considerable attention (e.g. Coldham, Addington \& Addington, 2002) but comparatively little research has explored factors associated with adherence to psychological therapy. Individuals' pre-existing beliefs about psychological therapy may impact on whether and how they engage with therapy (Hui et al, 2006; Lecomte et al 2008; Mutsatsa et al, 2003) and ambivalent attitudes may preclude engagement (Hazell et al, 2018; Ince et al, 2015). Beliefs and expectations can also influence individuals' experience of the therapeutic process and impact on outcome (Westra et al, 2010). A recent systematic review (Holding, Gregg \& Haddock, 2016) found that beliefs, attitudes, or expectations about therapy for psychosis have not been adequately explored. Research has tended to focus on individuals' therapy experience, including the process (what happens in therapy; how they are treated), outcomes (change, skills), and therapist characteristics. Relatively less data is available on the challenges of therapy and as such, findings are predominantly positive. Likewise, little information is available on people's expectations of therapy, and where studies have included questions about prior expectations, the questioning has largely taken place subsequent to completion of the therapy, which may introduce bias (Holding et al, 2016; Westra, Aviram, Barnes \& Angus, 2010). Moreover, the majority of data comes from people who have engaged with therapy, with very little from those who have dropped out or refused 
therapy altogether, and is therefore not representative of the views or beliefs of many who are eligible for psychosis services (Holding et al, 2016). To address these limitations we recruited participants with a varied therapy history and explored their beliefs and expectations about psychological therapy. We included people who had completed therapy, those who had declined therapy, those who had struggled to engage consistently in therapy, and those without prior experience of psychological interventions. Hence our study encompasses a broader range of therapy experiences than previous studies and highlights areas for exploration with clients before or during therapy in order to promote engagement and potentially improve outcomes (Ogrodniczuk, Joyce \& Piper, 2005; Westra et al, 2010).

Q methodology (Stephenson, 1953) was used as it aims to highlight and understand a diversity of viewpoints, including unheard or uncommon perspectives. Participants rank statements in relation to each other, which provides an overview of their viewpoint on the topic of interest (Stenner, Cooper \& Skevington, 2003). Q-methodology has been found acceptable for use in chronic and first episode psychosis populations (e.g. Jones, Guy \& Ormrod, 2003; Gregg, Haddock \& Barrowclough, 2009; Wood, Price, Morrison \& Haddock, 2013; Barr, Ormrod \& Dudley, 2015). It can be helpful when exploring complex concepts like beliefs, as it offers a broad range of accessible and acceptable responses, providing material for participants to reflect on and identify with (Dudley, et al, 2009). 


\section{Materials and Methods}

\section{Development of the $Q$ concourse}

The Q concourse for this study (the set of statements representing the range of beliefs about therapy) was derived from two main sources:

(1) Existing research literature on beliefs, expectations, or experiences of psychological therapy

(2) Semi-structured interviews with young people who have experienced symptoms of $\operatorname{psychosis}(n=11)$

The existing research literature

A systematic search of the literature was conducted using Ovid electronic database, including a combination of terms relating to psychological therapies; mental health, symptom or diagnostic profiles; and beliefs, experiences, or expectations. The search was not limited to psychosis since expectations or reasons for refusing or dropping out of therapy are lacking in psychosis research. Statements relevant to beliefs about therapy were extracted, including direct quotes or items from outcome measures or surveys. Only data from service users or people who had been offered therapy or were on a waiting list for therapy was considered; theoretical or mental health staff views were excluded. This process resulted in 27 articles from which 245 belief statements about therapy were extracted.

Interviews

A semi-structured interview exploring expectations and beliefs about therapy was administered to 11 people. All were White males in EIS with mean age of 28.82 
$(\mathrm{SD}=4.60)$ (range 21-36). Participants had recently taken part in a randomised controlled trial (RCT), the ReCAP Trial, which investigated the effectiveness of CBT combined with Motivational Interviewing (MiCBT) for young cannabis users with psychosis (Barrowclough et al, 2014). Four had been allocated to therapy (attending 1, 6, 17, and 22 sessions respectively) and seven had been allocated to treatment as usual. The schedule included questions about expectations of therapy and possible influences on these. Previous experiences of therapy and therapists, reasons for participating, declining and dropping out of therapy, including difficulties or challenges, were explored. Naïve participants were asked what they thought therapy might have been like. These interviews identified an additional 64 belief statements about therapy.

\section{Development of the $Q$ set}

The 309-item Q-concourse was reduced and refined in stages on the grounds of duplication and clarity, and to adjust language (see Stainton-Rogers, 1995) by the authors and a group of young people from a local mental health support group, aged 16-24. This resulted in a final Q-set of 64 statements. These were a mixture of general positive and negative beliefs about therapy, the setting or process, role expectations, perceived benefits (or lack of) including skills or improvement, medication, stigma, and other potential barriers.

\section{Other materials}

Additional information obtained from participants and their casenotes, included demographic details; psychological therapy history (mode, model and practitioner); brief substance use history and self-report symptomatology (Subjective Experiences of Psychosis Scale, SEPS, Haddock et al., 2011). The SEPS evaluates multi-dimensional 
experiences of psychosis. It contains 45 items, across 3 subscales, rated on a 5-point likert-type scale ranging from 1 (not at all) to 5 (very much). Subscales include: the positive and negative impact of psychotic experience on mental health and well-being, the positive and negative impact of support (such as treatment, support from friends or family) on psychotic experiences, and the severity of different dimensions of psychotic experiences (frequency, pleasantness) symptoms.

\section{Participants}

Participants were recruited from five EIS in Greater Manchester, Lancashire, Cheshire and Merseyside, UK, either as part of an exit interview following participation in an RCT or via referral from their EIS case manager. Participants were not required to have prior experience of psychological therapy to be eligible.

\section{Procedure}

The study was approved by an NHS research ethics committee (NRES North West: 08/H1015/82) and all participants gave informed consent. The first author and two research assistants administered the Q sort. Sixty-four numbered cards, each containing a single belief statement, were shuffled and given to participants for sorting onto an A1sized grid in accordance with their individual perspective. Participants were required to rank the cards from most agree to most disagree (figure 1.)

\section{[INSERT FIGURE 1 NEAR HERE]}

Recommended procedures for breaking the sorting task down into provisional ranking categories (agree, disagree, neutral) were followed (see Watts \& Stenner, 2012). 
Participants were encouraged to ask questions and make changes as required. Final card positions were recorded by the researcher and a brief post-Q interview was conducted to explore participants' ranking choices and obtain opinions of the task and topic. The Qsort and post-Q interview were digitally recorded to aid interpretation of factors.

\title{
Data analysis
}

Q-data were analysed using a dedicated software package (PQ Method v.2.35, Schmolck, 2002). Principle Components Analysis (PCA) with varimax rotation was employed, maximising the amount of variance explained by extracted factors. In $\mathrm{Q}$ methodology, factors demonstrate the relationship between participants, not between items, with each factor comprising participants who sorted statements similarly. Significant loading Q-sorts were identified to define each factor, which were then merged to produce factor arrays. These represent the best estimate or average of the Q-sorts for each factor. Factor arrays were interpreted in order to develop a summarizing account of the viewpoint being expressed by each factor (Watts and Stenner, 2005; Stainton-Rogers, 1995).

\section{Results}

Participants' demographic data, for the total sample and by individual factor, are reported in Table 1.

\section{[INSERT TABLE 1 NEAR HERE]}

\author{
PCA resulted in a four-factor solution, on which 24 of the Sorts loaded, \\ explaining $68 \%$ of the variance. Sixteen participants loaded on factor 1 (explaining 33\%
}


of the variance), three loaded on factor $2(8 \%)$, one on factor $3(12 \%)$, and four on factor $4(15 \%)$. Six sorts were excluded from the factor arrays (Table 2 ) as they loaded on multiple factors, and were therefore not considered in interpretation of factors below.

[INSERT TABLE 2 NEAR HERE]

\section{Interpretation of $Q$ Sorts}

For brevity, only summary interpretations are presented here. Full summaries are available from the corresponding author.

Factor 1 - "Therapy is helpful and gives hope for the future"

This factor included people who appeared to have globally strong positive views about psychological therapy, including its ability to bring about change, the process, and the people that deliver therapy. People who loaded on this factor believed that therapy 'provides support' $(+6)$, 'is helpful' $(+5)$, 'provides hope for the future' $(+4)$ and strongly disagreed that it was 'a waste of time' (-6). They appeared to believe that therapy provided a unique service, as they disagreed that therapy 'is not necessary, someone else could support a person's needs instead' (-3). People in this factor appeared to be generally ambivalent about medication as an adjunct to therapy (e.g. therapy 'is more helpful than taking tablets', 0) as well as other ways of getting help (therapy 'is not the only way for people to get help', 0) but strongly disagreed that medication is a replacement for therapy: Therapy 'is just talking, people need medication instead' (-6).

People in this group believed most strongly that therapy 'can help people make changes in their lives' $(+5)$, and disagreed that it 'only provides short term solutions' $(-3)$. 
They rated a number of change or positive outcome statements higher than people on other factors, for example: 'helps people cope with their experiences' $(+3)$ and 'helps people overcome stressful life events' $(+3)$.

They also appeared to have very positive beliefs about the process or setting in which therapy takes place, including how they would be treated and having a personal sense of control. They were the only group to disagree that therapy 'is guided by a therapist, not by the person' (-2) and strongly disagreed that it 'makes people make changes they don't want to make' (-5). For people in this group, therapy seemed to be a non-judgemental and non-stigmatising environment, which facilitates open and honest discussion, which may not be possible with family and friends. For example, they believed that therapy 'accepts people as they are without judging them' $(+6)$ and 'is somewhere people can talk about problems without being ashamed' $(+5)$.

Factor 2 - "Therapy is just talking, people need medication"

These three participants had strong views about the importance of medication. In contrast to factor 1 , they did not believe that therapy could be effective without other things in place, such as medication. Therapy was viewed as 'not the only way for people to get help' $(+5)$ and they disagreed that it 'is more helpful than taking tablets' $(-5)$. They believed that therapy 'is just talking, people need medication instead' $(+5)$ and 'is only helpful if the person is taking medication as well' $(+4)$. They were the only group to endorse that therapy 'is only for people with something wrong with them' $(+2)$

While medication seemed to be viewed as a necessity, they still held some positive general views about psychological therapy. They disagreed that therapy 'makes people's problems worse' (-6) and believed it 'helpful' (+6). They believed therapy is 
somewhere to: 'be listened to' $(+6)$, 'get self-understanding or insight' $(+4)$ and 'talk to someone who understands' (+3).

Unlike factor 1, they did not endorse many positive specific benefits to therapy and seemed to lack belief or hope that therapy could bring about change. For example, they disagreed that therapy 'can help people make changes in their lives' (-4) or 'helps people feel less distressed' (-5). They were uncertain about therapy in general, viewing it as 'an unknown which puts people off from trying it' $(+4)$.

Factor 3 - "Therapy is useful but stigmatising"

This participant expressed mixed views about therapy. He disagreed that therapy 'is somewhere people can talk about problems without being ashamed' (-3) and 'accepts people as they are without judging them' (-5), possibly leading him to disagree that therapy 'is somewhere people can talk honestly' (-6) and 'is somewhere people can talk about things that they are not comfortable telling family or friends' (-4). Moreover, he believed that therapy 'is something that people are too embarrassed to attend because of what other people would think' $(+4)$ and expressed the strongest concern compared to other factors that therapy 'makes people talk about things that will play on their mind later' $(+4)$. At the same time, he did have some positive beliefs about therapy: He agreed that therapy 'helps people understand the impact of the past on what is happening now' $(+6)$, 'helps people feel more confident in social situations' $(+6)$, and 'helps people get control over their problems' (+4).

\section{Factor 4 - "Therapy is better than medication"}

People in this group were the most strongly opposed to medication, disagreeing that therapy 'is only helpful if the person is taking medication as well' (-6) and 'is just 
talking, people need medication instead' (-4). However, they also appeared to be uncertain or ambivalent about whether therapy 'is helpful' (0) and could facilitate change in their lives but still believed it 'is more helpful than taking tablets' $(+3)$. They held the strongest positive beliefs about the therapy setting and how they would be treated. They expressed strong consistent beliefs that therapy 'is somewhere to be listened to' $(+6)$, 'is somewhere people are treated as individuals, not as an illness' $(+5)$, 'accepts people as they are without judging them' $(+4)$, 'is somewhere people can talk about things that they are not comfortable telling family or friends' $(+6)$, and 'is a respectful relationship between equals' $(+4)$. This could in turn influence beliefs about how they could be in sessions, endorsing that therapy 'is somewhere people can talk honestly' $(+5)$ and 'is somewhere people can talk about problems without being ashamed $(+3)$.

\section{Discussion}

This study aimed to explore young people's beliefs about psychological therapy for psychosis using Q-methodology and four distinct factors were identified. The results suggest that young people in EIS have complex and multi-faceted beliefs about different aspects of psychological therapy, including the process, normalisation and stigma, outcomes, and the people who deliver it. All participants had some level of positive belief about psychological therapy, albeit potentially for different reasons. In addition, interesting views about medication and usefulness in relation to therapy also emerged.

Factor 1/Therapy is helpful and gives hope for the future consisted of people who presented a strong case for psychological therapy. It represents just over half of the entire study sample. These views are in line with the current research available on 
peoples' beliefs about therapy for psychosis (Holding et al, 2016). They expressed positive views about all elements of the therapeutic process and believed that therapy played a unique role in supporting people in a non-stigmatising environment, in order to facilitate change and hope for the future.

Factor 2/Therapy is just talking; people need medication illustrates a more traditional view about therapy and medication. In sharp contrast to other groups they had strong views about the importance of medication being the only way to improve. They did not agree that therapy could accomplish change. It is possible that this group were less symptomatic and this view arose because they may differentiate themselves from 'less well' peers. However, they reported the lowest average score on severity of negative dimensions of psychosis and did not appear to differ from other groups with regard to frequency of psychotic symptoms. They are possibly more likely to endorse a medical or biological model explanation of the aetiology of psychosis and may feel that their difficulties are not psychological. They may have had these preconceptions before entering services, or may have been told that therapy is not helpful without medication for psychosis. This could be due to staff influences, who also often hold these views (Prytys et al, 2011) or may be attributable to the view that symptoms (such as voices) may get in the way of therapy (Hazell et al, 2017). Although there are arguments for psychological therapy for psychosis without medication (Morrison et al, 2012; 2018) current treatment guidelines endorse antipsychotic medication (NICE, 2014) and this is reflected in clinical practice.

Factor 3/Therapy is useful but stigmatising was the only one to voice a strong belief or worry that therapy could be a stigmatising, shaming, or judgemental experience, 
both because of the therapy process and because of what others might think. Some people might avoid mental health settings or treatment because they may be viewed as stigmatising, particularly if they have concerns about acceptance from peers and avoiding rejection (Gaebel et al, 2006). Young people with this view may be deterred from seeking help early which could negatively impact the duration of untreated psychosis and illness course. It must be noted that this factor was determined by one person's Q-sort. There is debate about whether factors of one should be retained or not, however support for this practice is available from two noteworthy Q-researchers: Brown (1980) and Stephenson (1964) posit that solitary or unique viewpoints can be significant, and as they may not constitute the 'norm', will not load onto other factors. These beliefs are certainly significant as stigma and social exclusion are common in the experience of psychosis (NICE, 2014).

Factor 4/Therapy is better than medication expressed the strongest beliefs against medication and about the way people are treated in therapy. It is interesting that these beliefs were held alongside ambivalence about the helpfulness of therapy, indicating uncertainty about anything being able to help.

\section{Strengths and limitations}

This study incorporated service user input at all stages of the research: they helped generate items for the Q-concourse, provided input on final item inclusion, terminology and design of the Q-set, and piloted the final materials. Factor summaries were reviewed and confirmed in line with a service user perspective with a Service User Development Worker, a former EIS user. This level of involvement throughout the study ensured that the content and materials were meaningful, representative and relevant from 
a service user perspective. While the development of the Q-set was performed systematically to be as inclusive as possible, it may not have included every belief. However, none of the participants suggested additional items for inclusion in the Q-set and they judged it to be comprehensive and representative of their beliefs.

The recruited sample may not be representative of EIS (or psychosis) populations and this research encountered similar limitations of previous studies in terms of sample characteristics. Participants were predominantly White males, who were engaged with services, and almost all had experiences of therapy. However, not all had completed or had helpful experiences of therapy, and described terminating therapy prematurely, which is in contrast to the majority of previous research exploring therapy experiences (Holding et al, 2016) and a further strength of this study.

Overall, a positive story has been told, however, this may be in part due to limitations in recruitment. More than two thirds of the sample had participated in an RCT of psychological therapy (the ReCAP trial, Barrowclough et al, 2014) and may be more likely to have held positive beliefs about therapy. Strategic sampling is acceptable and recommended in Q-research (Watts \& Stenner, 2012) and case managers were encouraged to identify Black and Minority Ethnic (BME) services users or people who have refused, dropped out, or may have negative views about therapy. Recruitment of these individuals proved difficult.

More than two thirds of participants met criteria for substance abuse at some point in the last 18 months (inclusion criteria for participation in the RCT). People with coexisting substance use may have additional needs and complexities compared to other service users with psychosis, and it is possible their beliefs may not be representative of 
EIS users as a whole (Cleary et al, 2008; NICE, 2011). However, substance use and abuse rates are high in FEP populations (Lambert et al, 2005), and it is important to consider beliefs about substance use as well when working with this population (Gregg et al, 2009). Nonetheless, this is the first study to explore beliefs about therapy from such a broad range of participants.

\section{Clinical implications}

Clinicians need to better understand service user concerns about therapy, as managing expectations and beliefs before therapy commences may facilitate better outcomes (Ogrodniczuk et al, 2005). Q methodology could be a useful tool for professionals across disciplines to assess expectations and beliefs for further exploration (Jones et al, 2003). Post sort interviews revealed that participants found Q less scrutinising and more enjoyable than traditional interview or questionnaire techniques. Negative beliefs are included in the Q-set, suggesting they are common and appropriate beliefs to hold, which may elicit more balanced accounts of beliefs.

Q can also facilitate useful content for discussions. These beliefs may be difficult to access, particularly with no prior experience of therapy. However, all people are likely to have beliefs about therapy, influenced by a number of sources, including media portrayals, which could lead to the development of faulty or unhelpful beliefs about therapy (Grazebrook et al, 2004). If these negative appraisals of therapy, such as fears or misconceptions about therapists, the process, and stigma go unexplored, and accurate explanations are not promoted, people may miss out on an important element of treatment. Clinicians should be mindful not to make assumptions about therapy beliefs based on previous therapy adherence. Service users can hold positive beliefs about 
therapy, despite finding it difficult to engage with. Conversations about potential barriers, including negative expectations, could help develop future care planning options, which may improve the chance for the service user to participate more fully in therapy in the future.

Previous research has identified potential barriers to therapy, such as concerns about cultural differences, confidentiality, implications of confidentiality breaches, therapy making symptoms worse, and not having a choice in therapy (Holding et al, 2016; Rathod, et al 2010; Westra et al, 2010). Few participants in this research had these concerns, possibly because the majority had previously taken part in an RCT, and this should remain a focus when discussing therapy.

An awareness of these beliefs may lead to different approaches or options being made available to service users. NICE guidelines for psychosis (2014) make recommendations for the use of peer support involving a trained peer support worker who has recovered from psychosis to provide advice and information. Meeting people who have recovered from psychosis, potentially with the help of therapy, could be both normalising and inspiring for people who may be hopeless, unsure about therapy or have concerns about stigmatisation. Voluntary support groups (such as the Hearing Voices Network) or group therapy approaches may also be particularly beneficial for those who feel isolated or stigmatised (Goodliffe et al, 2010; Newton et al, 2007; Romme \& Escher, 2000). 


\section{Future research}

The impact of therapy beliefs in psychosis has yet to be seen. Future research could explore the impact of beliefs about therapy on engagement and attrition, outcomes, and satisfaction. Studies would also benefit from alternative recruitment strategies to promote engagement for underrepresented groups in both research and mental health services, such as people who do not engage and BME groups. For some BME groups in particular, therapy dropout rates are higher and outcomes are poorer (Rathod et al, 2005; Turkington et al, 2002) and their beliefs about therapy may be less positive. Exploring beliefs in under-represented groups may help us to understand the potential impact of cultural beliefs on engagement with therapy.

\section{Acknowledgements}

We are grateful to the service users and staff who helped make this research possible. In particular, we would like to thank the young people at EPIC for contributing so thoughtfully to the development of the research. We also thank Neil Caton, Service User Development Worker, for taking the time to comment on results from the study.

\section{Declaration of competing interests}

The Authors declare that they do not have conflicts of interest. 


\section{References}

Barr, K., Ormrod, J., \& Dudley, R. (2015). An exploration of what service users value about early intervention in psychosis services. Psychology and Psychotherapy: Theory, Research and Practice, 88(4), 468-480. doi: http://dx.doi.org/10.1111/papt.12051

Barrowclough, C., Marshall, M., Gregg, L., Fitzsimmons, M., Tomenson, B., Warbutton, J., \& Lobban, F. (2014). A phase-specific psychological therapy for people with problematic cannabis use following a first episode of psychosis: a randomized controlled trial. Psychological medicine, 44(13), 2749-61. doi: http://dx.doi.org/10.1017/S0033291714000208

Brown, S. R. (1980). Political subjectivity. New Haven: Yale University Press.

Cleary, M., Hunt, G., Matheson, S., Siegfried, N., \& Walter, G. (2008). Psychosocial interventions for people with both severe mental illness and substance misuse. Cochrane Database of Systematic Reviews(1), CD001088. doi: http://dx.doi.org/10.1002/14651858.CD001088.pub2

Coldham, E. L., Addington, J., \& Addington, D. (2002). Medication adherence of individuals with a first episode of psychosis. Acta Psychiatrica Scandinavica, 106(4), 286-290.

Dudley, R., Siitarinen, J., James, I., \& Dodgson, G. (2009). What do people with psychosis think caused their psychosis? A Q methodology study. Behavioural and Cognitive Psychotherapy, 37(1), 11-24. doi: http://dx.doi.org/10.1017/S1352465808004955

Gaebel, W., Zaske, H., \& Baumann, A. E. (2006). The relationship between mental illness severity and stigma. Acta Psychiatrica Scandinavica, Supplementum(429), 41-45.

Goodliffe, L., Hayward, M., Brown, D., Turton, W., \& Dannahy, L. (2010). Group person-based cognitive therapy for distressing voices: views from the hearers. Psychotherapy Research, 20(4), 447-461. doi: http://dx.doi.org/10.1080/10503301003671305

Grazebrook, K. A., Siddle, R., Leadley, K., Everitt, J., Benn, A., Haddock, G., . . Tarrier, N. (2004). First Episode Psychosis: Two Cases to Illustrate the Role of Cognitive Behaviour Therapy in Making Sense of Unusual Experiences. Behavioural and Cognitive Psychotherapy, 32(3), 331-345. doi: http://dx.doi.org/10.1017/S1352465804001390

Gregg, L., Haddock, G., \& Barrowclough, C. (2009). Self-reported reasons for substance use in schizophrenia: a Q-methodological study. Mental Health and Substance Use: Dual Diagnosis, 2, 24-39.

Haddock, G., Wood, L., Watts, R., Dunn, G., Morrison, A. P., \& Price, J. (2011). The Subjective Experiences of Psychosis scale (SEPS): Psychometric evaluation of a scale to assess outcome in psychosis. Schizophrenia Research, 133(1-3), 244-249. doi: http://dx.doi.org/10.1016/j.schres.2011.09.023 
Jones, S., Guy, A., \& Ormrod, J. A. (2003). A Q-methodological study of hearing voices: a preliminary exploration of voice hearers' understanding of their experiences. Psychology \& Psychotherapy: Theory, Research \& Practice, 76(Pt 2), 189-209.

Lambert, M., Conus, P., Lubman, D. I., Wade, D., Yuen, H., Moritz, S., . . Schimmelmann, B. G. (2005). The impact of substance use disorders on clinical outcome in 643 patients with first-episode psychosis. Acta Psychiatrica Scandinavica, 112(2), 141-148.

Lecomte, T., Spidel, A., Leclerc, C., MacEwan, G., Greaves, C., \& Bentall, R. P. (2008). Predictors and profiles of treatment non-adherence and engagement in services problems in early psychosis. Schizophrenia Research, 102(1-3), 295-302. doi: http://dx.doi.org/10.1016/j.schres.2008.01.024

Morrison, A.P., Law, H., Carter, L. Sellers, R., Emsley, R.. Pyle, M. et al (2018). Antipsychotic drugs versus cognitive behavioural therapy versus a combination of both in people with psychosis: a randomised controlled pilot and feasibility study. The Lancet Psychiatry, 5 (5), 411-423. https://doi.org/10.1016/S2215-0366(18)30096-8

Morrison, A. P., Turkington, D., Wardle, M., Spencer, H., Barratt, S., Dudley, R., . . Hutton, P. (2012). A preliminary exploration of predictors of outcome and cognitive mechanisms of change in cognitive behaviour therapy for psychosis in people not taking antipsychotic 
medication. Behaviour Research and Therapy, 50(2), 163-0167. doi: http://dx.doi.org/10.1016/j.brat.2011.12.001

Mutsatsa, S. H., Joyce, E. M., Hutton, S. B., Webb, E., Gibbins, H., Paul, S., \& Barnes, T. R. (2003). Clinical correlates of early medication adherence: West London first episode schizophrenia study. Acta Psychiatrica Scandinavica, 108(6), 439-446.

Newton, E., Larkin, M., Melhuish, R., \& Wykes, T. (2007). More than just a place to talk: Young people's experiences of group psychological therapy as an early intervention for auditory hallucinations. Psychology and Psychotherapy: Theory, Research and Practice, 80(1), 127-149. doi: http://dx.doi.org/10.1348/147608306X110148

National Institute for Health and Clinical Excellence (2011). Psychosis with coexisting substance misuse: Assessment and management in adults and young people 120 London: National Institute for Health and Clinical Excellence.

National Institute for Health and Clinical Excellence (2014). Psychosis and schizophrenia in adults: treatment and management CG178. London: National Institute for Health and Clinical Excellence.

Ogrodniczuk, J. S., Joyce, A. S., \& Piper, W. E. (2005). Strategies for Reducing Patient-Initiated Premature Termination of Psychotherapy. Harvard Review of Psychiatry, 13(2), 57-70. doi: http://dx.doi.org/10.1080/10673220590956429

Rathod, S., Kingdon, D., Phiri, P., \& Gobbi, M. (2010). Developing culturally sensitive cognitive behaviour therapy for psychosis for ethnic minority patients by exploration and incorporation of service users' and health professionals' views and opinions. Behavioural and Cognitive Psychotherapy, 38(5), 511-533.

Rathod, S., Kingdon, D., Smith, P., \& Turkington, D. (2005). Insight into schizophrenia: the effects of cognitive behavioural therapy on the components of insight and association with sociodemographics--data on a previously published randomised controlled trial. Schizophrenia Research, 74(2-3), 211-219.

Romme, M., \& Escher, S. (2000). Making Sense of Voices: A Guide for Mental Health Professionals Working with Voice-Hearers: Mind Publications

Schmolck, P. (2002). PQ Method. Retrieved from http://schmolck.userweb.mwn.de/qmethod/downpqwin.htm

Stainton-Rogers, R. (1995). Q methodology. In J. A. Smith \& L. Van Langenhove (Eds.), Rethinking methods in psychology. London: Sage.

Stenner, P. H., Cooper, D., \& Skevington, S. M. (2003). Putting the Q into quality of life; the identification of subjective constructions of health-related quality of life using $Q$ 
methodology. Social Science \& Medicine, 57(11), 2161-2172.

Stephenson, W. (1953). The study of behavior: Q-technique and its methodolgoy. Chicago: University of Chicago Press.

Stephenson, W. (1964). Application of the Thompson schema to the current controversy over Cuba. The Psychological Record, 14(3), 275-290.

Turkington, D., Kingdon, D., \& Turner, T. (2002). Effectiveness of a brief cognitive-behavioural therapy intervention in the treatment of schizophrenia. The British Journal of Psychiatry, 180(6), 523-527. doi: http://dx.doi.org/10.1192/bjp.180.6.523

Villeneuve, K., Potvin, S., Lesage, A., \& Nicole, L. (2010). Meta-analysis of rates of drop-out from psychosocial treatment among persons with schizophrenia spectrum disorder. Schizophrenia Research, 121(1-3), 266-270. doi: http://dx.doi.org/10.1016/j.schres.2010.04.003

Watts, S., \& Stenner, P. (2005). Doing Q methodology: Theory, method and interpretation. Qualitative Research in Psychology, 2(1), 67-91.

Watts, S., \& Stenner, P. (2012). Doing Q methodological research: theory, method and interpretations. London: Sage.

Westra, H. A., Aviram, A., Barnes, M., \& Angus, L. (2010). Therapy was not what I expected: a preliminary qualitative analysis of concordance between client expectations and experience of cognitive-behavioural therapy. Psychotherapy Research, 20(4), 436-446. doi: http://dx.doi.org/10.1080/10503301003657395

Wood, L., Price, J., Morrision, A., \& Haddock, G. (2013). Exploring service users perceptions of recovery from psychosis: A Q-methodological approach. Psychology \& Psychotherapy: Theory, Research \& Practice, 86(3), 245-261. doi: http://dx.doi.org/10.1111/j.2044$\underline{8341.2011 .02059 . x}$ 